\title{
LANK LEEF DIE DOOIES: \\ OOR POSTMORTEM FOTOGRAFIE, DODEMASKERS, GELOOFSGETUIES, VOORVADERS EN DOMINEE-PORTRETTE
}

\begin{abstract}
Cas Wepener
Fakulteit Teologie

Universiteit van Stellenbosch

Abstract

By making use of qualitative interference as methodological starting point, this article sets out to compare some "qualities" inherent in five distinct phenomena. The phenomena under scrutiny are postmortem photography, death masks, saints, ancestors and portraits of ministers. Each one of these phenomena is firstly (briefly) opened as a source in order to shed light on some of it's important aspects. Secondly some qualities that were derived from these sources are compared for qualitative interference. This is done to show that the essence of photography as a medium makes it an excellent source for the inculturation of the honoring of the ancestors (the so-called living dead) in the liturgy of African churches.
\end{abstract}

\section{Inleiding}

In die film The Others met Nicole Kidman in die hoofrol, het 'n opmerking oor foto's van lyke opgeval. Volgens dié film was daar in die negentiende eeu só 'n sub-genre binne fotografie met die oogmerk om aan die gestorwe subjekte onsterflikheid te verleen. Oor die reële bestaan van hierdie foto's bestaan geen twyfel nie, en in Suid-Afrika bestaan daar ook menige voorbeeld van hierdie gebruik van fotografie, maar by die film se verduideliking van die betekenis van hierdie foto's kan nog die een en ander opmerking gevoeg word.

Hoe dit ook sy, die intensie waarmee fotografie as medium hier aangewend is, is nie nuut nie. Hierdie gebruik kom al in antieke kulture voor soos byvoorbeeld Tutenkamen se dodemasker. Pogings om deur middel van visuele artefakte die dood te verdryf, of te ontken, of om aan gestorwenes onsterflikheid te verleen, is so oud soos die mensdom self. Maar behalwe onsterflikheid, was dit ook pogings tot onthou, tot memento mori. Die herinnering aan geliefdes wat die lewendes of oorlewendes vooruitgegaan het na die onbekende, die hiernamaals.

Vervolgens sal die verband tussen fotografie en die dood, asook die gebruik en betekenis van dodemaskers eerstens verken word. Daarna sal die "lewende dooies" van Afrika, die geloofsgetuies van die Bybel, en die dominee-portrette wat in baie protestantse kerke se konsistories hang, verken word. Dít sal alles gedoen word om uiteindelik met behulp van die begrip inkulturasie te kyk of daar enige verbande gelê kan word tussen die inkulturasie van die "herinnering aan die voorouers" in die liturgie, en die dominee-portrette in die protestantse tradisie. Met ander woorde, daar word in hierdie artikel gevra of die domineeportrette oor inkulturatiewe potensiaal ten opsigte van die voorouers binne 'n Afrikakonteks beskik, al dan nie? 'n Vraag wat gevra word teen die agtergrond van die feit dat daar 'n wesenlike behoefte bestaan in Afrika-kerke om op 'n teologies-verantwoorde wyse om te gaan met die herinnering aan hul voorouers in die liturgie. Deurgaans sal enkele 
eksemplariese foto's en kunswerke ook as bron aangewend en geïnterpreteer word met behulp van insigte van die sogenaamde veld van die Visuele Antropologie. ${ }^{1}$

\section{Postmortem fotografie}

'n Handige onderskeid wat Post maak, is om te onderskei tussen 'n identifiserende en interpretatiewe fase wanneer foto's as bron vir navorsing aangewend word. Saam hiermee gee hy ook die onderskeid tussen die vaste, die beweegbare en die lewendige elemente in die foto's. "If a hierarchy can be established among them, then one is well on the way to sound identification and interpretation". ${ }^{2}$ In hierdie ondersoek is die vaste punt telkens 'n liggaam, veral 'n gesig. Die beweegbare element is lewe, en sy teenhanger, dood, asook die konteks waarbinne die foto geneem is en waarbinne die kyker dit nou sien. En die lewendige element sou die verskillende gebruike van die verskillende soorte foto's wees. Teen hierdie agtergrond sal nou eerstens na postmortem fotografie gekyk word.

Postmortem fotografie was wydverspreid in Europa en die VSA gedurende die negentiende eeu, ${ }^{3}$ en gevolglik ook in Europese kolonies soos Suid-Afrika. Hierdie foto's se subjekte is lyke en is op verskillende wyses gefotografeer. Die eerste meegaande foto is die dié van 'n meisietjie wat geneem is in die negentiende eeu. Hierdie voorbeeld (figuur 1) was een van die meer algemene tipes. Eerstens was die meeste foto's uit hierdie periode van kinders vanweë die hoë persentasie kindersterftes, tweedens was die subjek op 'n bed gefotografeer, derdens is die meisietjie versorg in terme van byvoorbeeld kleur op haar wange, mooi klere, en laastens is sy uitgebeeld asof sy slaap. ${ }^{4}$

Figuur 1:

Postmortem foto

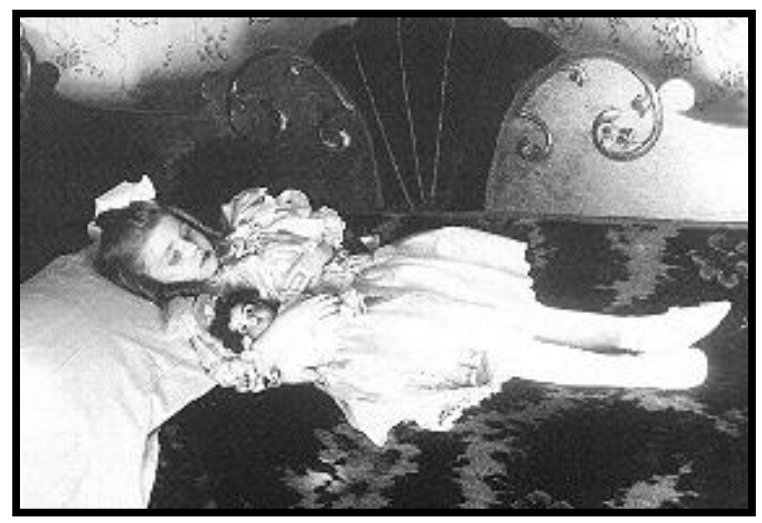

1. Veral die werk van Roland Barthes, 1980. Camera Lucida. Reflections on Photography. New York: Hill \& Wang, sal hier gebruik word. Sien ook, Susan Sontag, 1990. On Photography. New York: Anchor Books Doubleday, asook, El Guindi, F. 1998. "From Pictorializing to Visual Anthropology". In: Bernard, HR (red.). Handbook of Methods in Cultural Anthropology. Walnut Creek/Londen/New Delhi: Altamira Press, en Harper, D 1994. "On the Authority of the Image. Visual Methods at the Crossroads". In: Denzin, NK en Lincoln, YS. Handbook of Qualitative Research. Thousand Oaks/Londen/New Delhi: Sage Publications. Vir 'n goeie oorsig van bronne op hierdie terrein, sien voetnoot 5 van, Post, PGJ 1995. "An excellent game...": On Playing the Mass. In: Caspers, Lukken en Rouwhorst (reds.). Bread of Heaven. Customs and Practices surrounding Holy Communion. Essays in the History of Liturgy and Culture. (=Liturgia Condenda 3). Kampen: Kok Pharos Publishing House, p. 186-187.

2. Post, PGJ 1995, p. 187.

3. Sien, Meinwald, D "Memento Mori: Death and Photography in Nineteenth Century America". http://www.cmp.ucr.edu/terminals/memento_mori/intro.html, asook, Kenney, L "Death, Photography and God (not necessarily in that order)”. http://www.csun.edu/ hbthe056/mw2.html

4. Vergelyk ook Meinwald se analises. Is dit moontlik om 'n verband te lê tussen die uitbeelding van dooie kinders in foto's soos hierdie een en prente van Sneeuwitjie in kinderboeke? Al word die illusie van fiksie soms in postmortem fotografie geskep, bly dit waar. En dít maak fotografie essensieël anders as skilderkuns (vgl. Magritte se skildery). 
Daar was ook ander wyses waarop lyke uitgebeeld is in fotografie, byvoorbeeld waar die plasing ' $n$ kis is of waar die oorledene in ' $n$ sittende posisie afgeneem is, of waar die subjek uitgebeeld is asof hy/sy lewe en dat die aanwesigheid van die dood dan deur simbole aangebring is op die foto. ${ }^{5}$ Hoe dit ook al sy, wat vir hierdie artikel meer van belang is, is die betekenis, of die doel waarvoor hierdie foto's geneem en aangewend is.

Volgens Meinwald was portret-foto's oor die algemeen besonder belangrik gedurende die negentiende eeu, aangesien so 'n portret 'n uitdrukking was van die persoon se identiteit en individuele waarde, en met postmortem foto's was dit selfs nog meer die geval. ${ }^{6}$ 'n Verdere funksie was om die oorledene as slapende uit te beeld "It had a sentimental appeal in the nineteenth century, as it corresponded to the urge to symbollically maintain the presence of the deceased person within the circle of the family. Someone who is asleep may, after all, wake up, if only in the dreams and fantasies of the living". Behalwe slaap is die subjekte soms, soos reeds vermeld, as lewend uitgebeeld wat die ontkenning en verwerping van die persoon se dood eintlik nog een stap verder neem. ${ }^{7}$

Wat hierdie foto's aangrypend maak, is wat Barthes ${ }^{8}$ beskryf as iets wat deel is van die essensie van die aard van fotografie, naamlik dat die objek wat die kyker sien werklik bestaan het en dáár was waar die kyker hom of haar op die betrokke foto waarneem. So 'n foto bring die aanskouer dus op 'n akute wyse in bykans reële aanraking met die dood (van iemand). Die lig wat uitgegaan het van daardie dooie persoon en eens op 'n tyd vasgevang is deur ligsensitiewe silwer halogeen, is lig wat nou weer van die foto af uitgaan en op die kyker se blik val. Tyd, of eerder die tydelikheid van tyd, sterflikheid, dring deur die kyker se pupil tot op sy/haar iris. En dít op 'n ander wyse as 'n skildery of beeldhouwerk van 'n dooie persoon wat steeds 'n element van fiksie inhou. Daar is altyd nog die moontlikheid dat dit nie presies so daar uitgesien het nie. Die dood van die subjek in postmortem fotografie is egter geen fiktiewe aangeleentheid nie. Volgens Barthes is 'n foto nooit van sy referent te onderskei nie en 'n pyp hier altyd 'n pyp.' En volgens Grimes ${ }^{10}$ is die aanskouing van 'n lyk se gesig altyd 'n roerende ervaring. Tog sien 'n mens ook deur hierdie foto's iets van die misterie van lewe en ervaar die kyker ten aanskoue van so 'n foto iets van Van Wyk Louw se versreël, "mooi is die lewe en die dood is mooi". 11

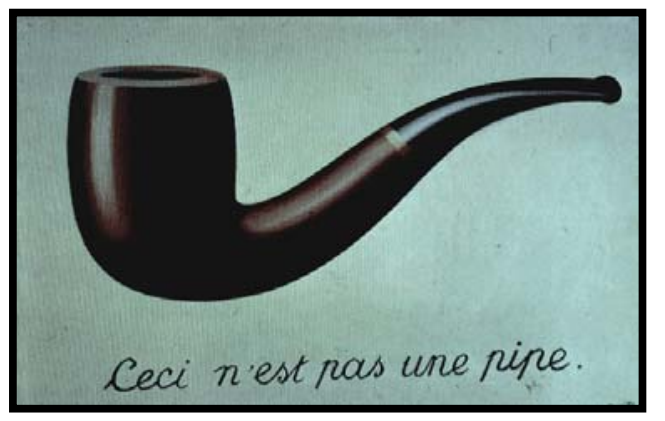

Figuur 2

René Magritte

5. Voorbeelde van sulke simbole is 'n roos wat onderstebo vasgehou word deur die subjek, 'n gebreekte blomsteel wat verwys na 'n kortgeknipte lewe, 'n "morning glory" wat blom, verlep en afval in minder as 'n dag, 'n boot op kalm water simboliseer 'n maklike dood en 'n boot op stormwater 'n moeilike dood, en dan natuurlik die meer voor die hand liggendes soos 'n treurwilger en 'n grafsteen. Sien, Meinwald, D.

6. Sien, Meinwald, D. "Memento Mori: The Body". http://www.cmp.ucr.edu/terminals/memento_mori/body.html

7. Ibid. In ander gevalle is die subjekte soms afgeneem in selfs 'n staande posisie met geverfde ooglede asof hulle oë oop sou wees, sien, Kenney, L "Death, Photography and God (not necessarily in that order)".

8. Vergelyk, Barthes, R 1980, p. 115.

9. Ibid., p. 5.

10. Sien, Grimes, RL 1995. Beginnings in Ritual Studies. Revised Edition. Columbia, SC: University of South Carolina Press , p. 80

11. Louw, NP Van Wyk 1984. Die Halwe Kring. Kaapstad: Tafelberg Uitgewers, p. 30. 
'n Pastorale sielkundige van Kaapstad, Marius Brand, beskryf ook onlangs aan die ondersoeker die pastorale gebruik van fotografie met stilgebore kinders. Hier help die foto wat van die ma (soms ook pa) met die dooie kind in haar arms in die hospitaalbed geneem word die ouers om uiteindelik die kind se lykie af te gee en die hartseer te verwerk. 'n Ander meer bekende pastorale gebruik is die waarde wat die agtergeblewenes heg aan foto's van geliefdes (van toe hulle nog geleef het). Die bekende foto op die lessenaar of die foto op die spieëltafel, of selfs net ' $n$ foto in 'n beursie. ${ }^{12}$ In sekere lande, byvoorbeeld Griekeland (soms ook in Suid-Afrika), is dit ook die gebruik om 'n foto van die oorledene op sy of haar grafsteen aan te bring.

'n Laaste voorbeeld hang saam met die opkoms van Spiritualisme in die negentiende eeu, waar sekere fotograwe die geleentheid benut het, en die menslike gees wat die liggaam oorleef het, gefotografeer het. Hierdie foto's het as 'n bewys gedien vir die bestaan van 'n lewe, geestelik, na die dood. "The person desiring a photograph of a deceased friend or relative would simply pose as if for their own picture. The spirit 'extra', as it was called, did not appear in the studio, but in the negative and the subsequent print". ${ }^{13}$ Hierdie tipe fotografie het onder andere in Amerika, Engeland en Frankryk voorgekom en Meinwald merk op dat dit interessant is om te sien dat die Britse spoke anders daar uitgesien het as die Amerikaanse spoke. ${ }^{14}$ Desnieteenstaande het hierdie tipe fotografie 'n ware behoefte aangespreek, te wete die behoefte aan die versekering dat daar lewe na die dood is.

Hier is dus enkele voorbeelde uit die geskiedenis van fotografie van hoe foto's dikwels 'n funksie vervul het met betrekking tot afgestorwenes. En met enkele uitsonderings na, was die funksie van hierdie foto's om te onthou, om die tydelike aard van die menslike bestaan met behulp van fotografie te transendeer, en om die oorlede persoon bykans as lewende in die hede te onthou. Om die proses waardeur die menslike geheue, veral na die dood van 'n geliefde, deur tyd vervaag word, te stuit. 'n Proses wat positief helend en/of negatief verwyderend, as 'n verlies, ervaar kan word. En oor die gebruik van foto's met betrekking tot die dood kan afhangende van die individuele situasie positief of negatief geoordeel word. Vir hierdie ondersoek is dit belangrik om hierin te sien hoe foto's dikwels as 'n medium gebruik is, en steeds gebruik word, om die gedagtenis aan die dooies lewend te hou. Ten slotte is dit belangrik om tradisionele postmortem fotografie as 'n verskynsel binne die negentiende eeuse konteks en die gangbare houding ten opsigte van die dood te verstaan.

\section{Dodemaskers}

Die vraag wat Grimes homself afvra in sy ondersoek na maskering, is hoe die daad van maskering geïnterpreteer kan word? Hoe daardie simboliese aksie, daardie soos wat hy dit noem "maak van 'n tweede gesig" geïnterpreteer kan word.

Volgens Grimes gebeur "concretion" wanneer 'n "human exterior is interpreted as the bodying forth or fixing of an external power". ${ }^{15}$ Hierdie gevolgtrekking verduidelik hy onder andere aan die hand van die gebruik van dodemaskers in negentiende eeuse Europa. Grimes ${ }^{16}$ haal vir Lommel aan volgens wie die dodemasker die prototipe van alle maskers is. Doodgaan, net soos maskering, is 'n rigidifiserende proses. "In view of many people, personhood, though it remains effective after death, nevertheless is fixed by death. The

12. 'n Roerende voorbeeld in hierdie verband is Roland Barthes se beskrywing van die waarde wat hy na sy ma se dood geheg het aan 'n foto van sy ma waar sy 'n klein dogtertjie is. Barthes, R 1980, p. 67-71.

13. Meinwald, D. "Memento Mori: The Afterlife". http://www.cmp.ucr.edu/terminals/memento_mori/afterlife.html

14. Ibid.

15. Grimes, RL 1995, p. 79.

16. Ibid., p. 80. 
fixed is not to be confused with the powerless. In fact, a death mask is a means of appropriating the power of deceased personhood. To die is not to become powerless, but to become powerfull in a fixed mode". ${ }^{17}$ Om te sterf, is om te val in 'n rigidityd, en om die dooies te maskeer is 'n getuienis van die krag van dié uiterlike. Deur maskering word 'n bonatuurlike krag ontmasker. ${ }^{18}$ In Europa is lewensgrootte was-effigieë en mannekyne gemaak wat gemodelleer is asof die oorledene nog lewe, en sodoende kon hy/sy oor hulle eie graf regeer deur die maskers, al was die lyk van die oorledene in 'n kis. So byvoorbeeld is 'n effigie van Marat gemaak in 1793 en vir revolusionêre propaganda aangewend. ${ }^{19}$

'n Dodemasker is 'n grensteken wat twee misteries, lewe en dood, skei. ${ }^{20}$ Grimes haal vir Benkard ${ }^{21}$ aan volgens wie Lessing (†1781) se dodemasker die eerste voorbeeld is van 'n masker wat slegs met die oog op eerbied gebruik is, en sê, "the death mask becomes symbolic of the faith that death, though it parts us, can never dissolve a spiritual bond". Die dodemasker word met ontsag bejeën as gevolg van dít wat die masker kan effektueer, maar afgesien daarvan of die masker sy krag van magiese kousaliteit of geheue ontleen, stel dit 'n statiese krag (dunamis) voor. "At once a living-dead thing and a dead-living being". ${ }^{22}$ Die masker is dus nie net die grens tussen lewe en dood nie, maar oorskry ook daardie grens. 'n Dodemasker sou 'n mens kon sê beskik oor die kwaliteit om die verlede (die lewe en persoon van die oorledene) deur middel van die artefak in die hede te onthou, en deur die proses van onthou op 'n sekere wyse die oorledene of sy/haar dunamis vir die aanskouer teenwoordig te stel. Teen hierdie agtergrond sal die "lewende dooies" van Afrika vervolgens verken word.

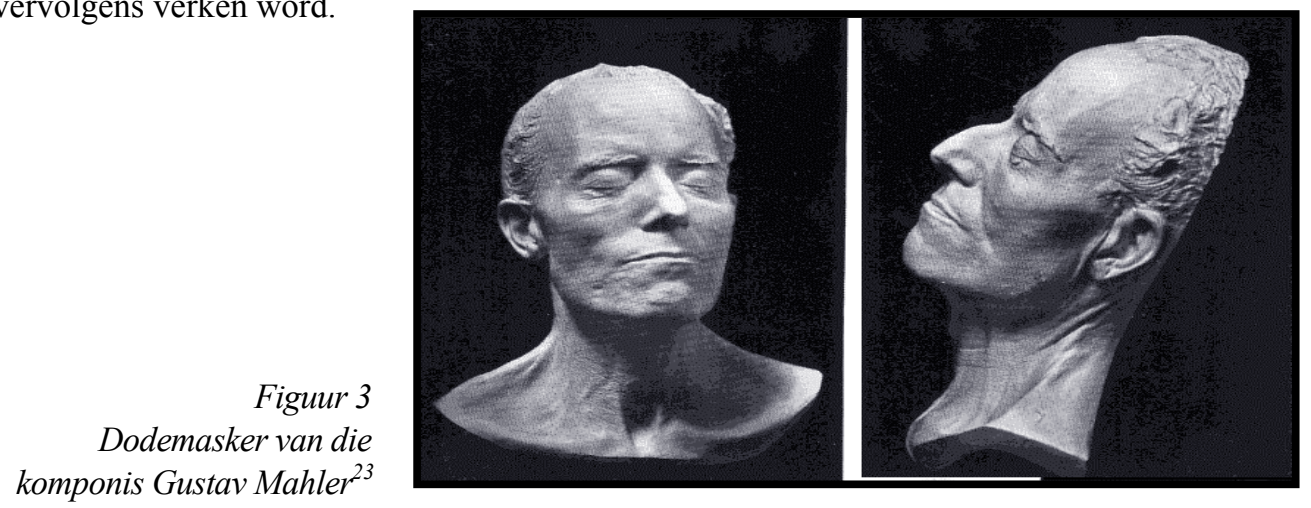

\section{Die lewende dooies}

In 'n inleiding oor Afrika-teologie, sowel as in sy proefskrif, ${ }^{24}$ weerlê Setiloane die tradisionele Westerse verstaanswyses van die betekenis van voorouers in tradisionele Afrika-godsdienste en die Christelike geloof in Afrika. Volgens Setiloane was die sende-

17. Ibid.

18. Ibid.

19. Ibid.

20. Ibid.

21. Benkard, E 1929. Undying Faces: A Collection of Death Masks. Londen: Hogarth, en Grimes, RL 1995, p. $80-81$.

22. Grimes, RL 1995, p. 81.

23. Uit, Benkard, E 1929. Undying Faces: A Collection of Death Masks. Londen: Hogarth.

24. Setiloane, GM 1976. Images of God among the Sotho-Tswana. Rotterdam: Balkema. Die bron van Setiloane wat hier gebruik is is, Setiloane, GM 2000. African Theology. An Introduction. Kaapstad: Lux Verbi, veral p. 29-33. 
linge in hulle werk en geskrifte bevooroordeeld teenoor die "lewende dooies" of voorouers, en het veral Moffat die Westerse denkwyse ten opsigte van voorouers beïnvloed. Die basiese fout wat hulle gemaak het, was om die voorouers (Badimo) met God (Modimo) te vereenselwig, terwyl die voorouers binne die Afrika ervaring eerder mense as gode of geeste is. ${ }^{25}$ Sodoende is kontak met die voorouers 'n persoon-tot-persoon kontak, en maak Setiloane sterk kapsie teen benamings soos "voorvadergeeste". ${ }^{26}$ Net so verwerp Afrika volgens hom ten sterkste die suggestie dat hulle die voorouers aanbid, en verkies hulle eerder die woord diens (tirelo) as aanbidding. ${ }^{27}$

Voorouers is binne 'n Afrika verstaan van die wêreld 'n onontbeerlike deel van die geheel. "If we compare the interaction of vital forces in the universe to a spider's web, then in day to day life the ancestors form the principal strand without which the fabric collapses" ${ }^{28}$ Die voorouers is in die eerste plek die stigters van die stam aan wie hulle ook hulle name ontleen, en daarna alle dooies van die stam volgens die orde van eersgeboortereg, wat hulle vitaliserende invloed op die lewendes uitoefen. ${ }^{29}$ 'n Invloed wat bestaan uit beskerming sowel as kritiek en straf, en die basiese beginsel is die van aanwesigheid. "The ancestors, though dead, are present and continue to influence life in their erstwhile communities on earth". ${ }^{30}$

'n Probleem wat Christene met die voorouerverering kan hê, is dat die voorouers soms funksies vervul wat Christene slegs aan God toeskryf, funksies soos beskerming en straf van die lewendes. Tog is Crafford ${ }^{31}$ van mening dat die behoefte wat daar in Afrika bestaan om die voorouers te vereer, nie geïgnoreer kan word nie en wys hy op enkele moontlike benaderings. Waar die gebruik deur Protestante as bygeloof afgewys is, het mense dit meesal in die geheim voortgesit. Die Rooms Katolieke Kerk het die gebruik dikwels meer geakkommodeer en die voorouers in die communio sanctorum opgeneem, sonder die nodige Skriftuurlike kritiek. Laastens onderskei sekere onafhanklike Afrika kerke tussen die voorouers van gelowiges en ongelowiges, waar die voorouers van ongelowiges as skadelike demone gesien word, die afgestorwe gelowiges as deel van die gemeenskap gesien en vereer word. "Die oplossing vir die probleem moet daarin gesoek word dat daar oor die voorouers gepraat mag word, maar nie met hulle nie. Hulle mag in herinnering geroep word, maar hulle mag nie die voorsienigheid van God, die middelaarskap van Christus en die gemeenskap van die Heilige Gees vervang in inheemse kerke in Afrika nie". ${ }^{32}$

25. Sien, Setiloane, GM 2000, p. 63. Hy vertaal hier Modimo as "The One who penetrates all being/existence". Sien ook p. 34-42. Verder kwalifiseer hy die voorouers as die ervaring van die numineuse, hulle is nie so menslik dat hulle oor geen goddelikheid beskik nie. Hulle is 'n bietjie minder as hemelse wesens (Ps. 8) én hulle is alreeds dood en só is hulle in Afrika nog nader aan God. Vergelyk, p. 31-32.

26. Ibid., p. 30.

27. Ibid., p. 31, asook, Crafford, D 1996. "Tradisionele godsdienste in Afrika". In: Meiring, P (red.). Suid-Afrika. Land van baie godsdienste. Pretoria: Kagiso, p. 16, wat prontuit sê dat dit verkeerd is om van vooroueraanbidding te praat. Verster, P 1997. Wie het die waarheid beet? 'n Vergelykende oorsig van die Christendom en die groot godsdienste van die wêreld. Vereeniging: CUM, bespreek die voorouers net in terme van kwaad wat die voorouers veroorsaak indien hulle nie vereer en tevrede gehou word met offers nie. Hierteenoor is Setiloane se fokus wanneer hy oor die voorouers skryf baie meer op die positiewe en praat hy self eerder van die voorouers as 'n "life force".

28. Magesa, L 1997. African Religion. The Moral Traditions of Abundant Life. Maryknoll, NY: Orbis Books, p. 47.

29. Ibid.

30. Ibid., p. 48.

31. Sien, Crafford, D. 1996, p. 16.

32. Ibid., p. 17. 
Vervolgens sal gekyk word of tradisionele Westerse kerke in Suid-Afrika, soos die NG Kerk, nie 'n eie unieke tradisie van voorouerverering het deur middel van portrette nie. Voordat dit egter gedoen word, sal enkele opmerkings met betrekking tot die hedendaagse protestantse herinnering aan geloofsgetuies belig word.

\section{5. 'n Wolk van getuies}

In sommige protestantse kringe is daar vandag hernude belangstelling in die gedagtenis van geloofsvoorgangers. ${ }^{33}$ Die begrip "heiliges" is egter in dié verband kontensieus. Daarom gebruik liturgiste soos Schuman eerder die terme voorganger, getuie of gids, en wys daarop dat dit om die "gemeenskap van die heiliges" gaan, wat verby die dood heen strek. ${ }^{34}$ In die Skrif kan verskeie tekste die gebruik om diegene wat ons in die geloof voorgegaan het, en na hul dood herinner/onthou word, staaf. 'n Voorbeeld hiervan is Hebr. 11: 39-40, "En hoewel daar oor hulle almal vanweë hulle geloof met soveel lof getuig is, het hulle nie verkry wat beloof is nie, omdat God vir ons iets beters beoog het, sodat hulle nie sonder ons die voleinding sou bereik nie". Hebr. 13:7 lui, "Dink aan julle voorgangers wat die woord van God aan julle verkondig het. Let op hulle lewenswandel tot die einde toe, en volg die voorbeeld van geloof wat hulle gestel het". Schuman noem verder ook Hebr. 11 as 'n geheel waar een na die ander geloofsgetuie opgenoem word, asook Openb. 6: 9-11 se verwysing na mense met die witte klere aan. Vir Schuman is die Bybelse fundering sterk Die vraag is egter hoe daar op hierdie fundering voortgebou kan word? ${ }^{35}$

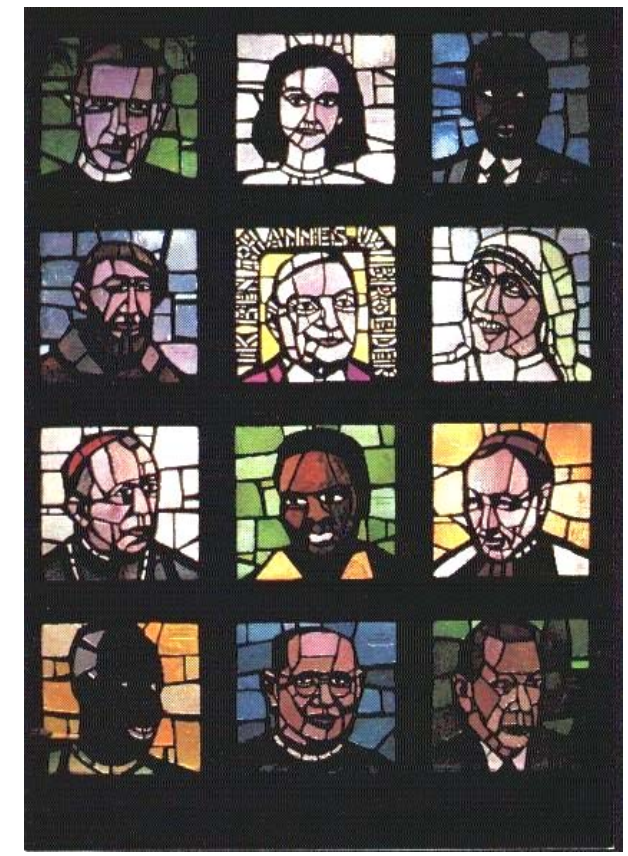

Daan Wildschut, glas in betonraam ${ }^{36}$

33. Vergelyk, Schuman, N 1998. "Getuigen”. In: Oskamp, P en Schumann, N (reds.). De weg van de liturgie. Tradities, achtergronden, praktijk. Zoetermeer: Meinema, p. 144.

34. Ibid.

35. Ibid., p. 144. In die res van die gedeelte beskryf hy dan ook hoe hierdie praktyk in die loop van die geskiedenis ontwikkel het, p. 144-152. Vir 'n oorsig met betrekking tot heiligeverering in die geskiedenis van die Christelike liturgie sien, Wepener, CJ 2000. Liturgie en versoening. Die inkulturasie van rituele van versoening in Suid-Afrika ('n ondersoeksvoorstel). Universiteit van Stellenbosch, p. 44-87.

36. Hierdie venster wys wat moontlik is ten opsigte van 'n meer inklusiewe uitbeelding van voorgangers. Die mense in die raam is van links na regs van bo na onder, Teilhard de Chardin, Anna Frank, Martin Luther King, abbé Pierre, pous Johannes, Theresa van Calcutta, Helder Camara, Steve Biko, Wilhelmus Becker, Julius Nyere, Dietrich Bonhoeffer en Dag Hammerskjöld. Vir meer oor dié raam en kerk sien, http://members.home.nl/annakerk/kerk.htm 
Een wyse waarop die geloofsgetuies in die geskiedenis van die Christelike kerk onthou is, was deur middel van getuieniskalenders. Met betrekking tot getuieniskalenders het daar naas die tradisionele kalenders ook ekumeniese kalenders ontstaan. Hierdie kalenders poog om ook musici, skilders, beeldhouers, skrywers ensovoorts in te sluit, asook mense uit die meer resente geskiedenis, ${ }^{37}$ en aksentueer soms ook politieke en maatskaplike betrokkenheid van geloofsgetuies. Voorbeelde van hoe hierdie getuieniskalenders ritueel tot uitdrukking kom, is in getyedienste, en as hulp vir voorgangers en liturgiegroepe om by nagmaalsvieringe die kring van nou lewende deelnemers te sluit met die gedagtenis van ander. ${ }^{38}$

Behalwe in getuieniskalenders is/word die herinnering aan voorgangers ook dikwels op 'n visuele wyse uitgebeeld. Die venster waarop geloofsvoorgangers afgebeeld is in die Anna kerk te Heerlen is 'n voorbeeld hiervan. ${ }^{39}$

\section{Dominee-portrette}

Alhoewel die idee van "heiliges" soos wat dit in die geskiedenis van die Christelike liturgie gebruik is, asook die verering van voorouers soos wat dit binne die Afrika-konteks voorkom, vreemd is aan die gereformeerde tradisie, het die gereformeerde kerke en vele ander protestantse denominasies tog op 'n eie outentieke wyse mense vereer. 'n Spesifieke voorbeeld is die dominee-portrette wat in die meeste konsistories van die NG Kerk in Suid-Afrika voorkom, asook die portrette van die hoogleraars teen die mure van byvoorbeeld die Fakulteit Teologie van die Universiteit van Stellenbosch. Hierdie portrette dien nie net as dokumentasie van wie as leraars en hoogleraars gedien het nie, maar oefen ook 'n invloed uit op diegene wat die portrette sien deur middel van visuele kommunikasie. ${ }^{40}$

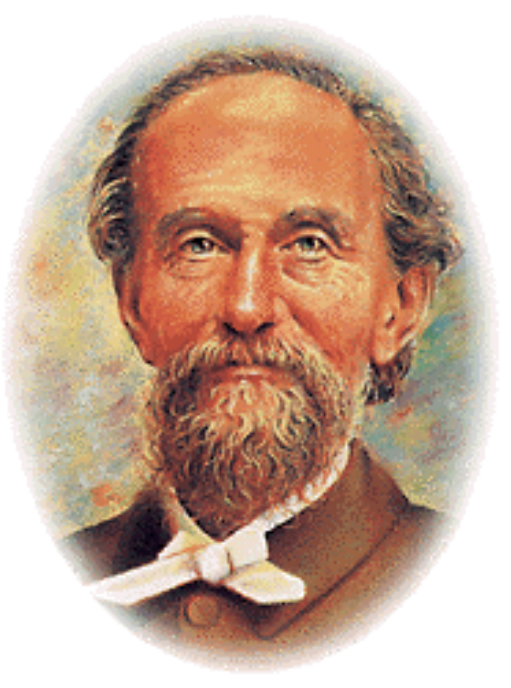

Figuur 5

Portret van Andrew Murray snr.

37. Byvoorbeeld, 28 Januarie - Feodor Dostojewski; 18 Februarie - Michelangelo Buonarotti; 4 April - Martin Luther King en 10 Desember - Karl Barth. Schuman, N. 1998. "III. Een getuigenkalender”. In: Oskamp, P. en N Schuman (reds.). De weg van de liturgie. Tradities, achtergronden, praktijk. Zoetermeer: Meinema, p. $450-453$.

38. Schuman, N 1998, p. 149-150.

39. Sien, Stock, A 2001. “22B. Litanieën”. In: Barnard, M en Post, P (reds.). Ritueel bestek. Antropologische kernwoorden van de liturgie. Zoetermeer: Meinema, p. 312.

40. Dit sal geldig wees om te vra in hoe 'n mate lidmate in kontak kom met hierdie portrette, aangesien die portrette hoofsaaklik net in konsistories hang? Eerstens kom lidmate op 'n bykans daaglikse basis in aanraking met die mense wie afgebeeld of gefotografeer is. Tweedens vergader kerkrade ten minste eenmaal per week in die konsistorie omring deur hierdie beelde, hetsy vir 'n vergadering of vir gebedsbyeenkomste. Derdens word daar in baie gereformeerde kerke liturgiese byeenkomste soos bidure in die konsistorie gehou. Laastens kan ook opgemerk word dat predikante van die Nederduitse Gereformeerde Kerk gedurende hulle teologiese opleiding vir ses jaar lank met hierdie beelde saamleef. 
Frijhoff vra tereg of hierdie portrette nie 'n kompensasie was vir die beeldloosheid in die religieuse domein nie ${ }^{41}$ Was hierdie portrette wat steeds die wande van baie protestantse loca sancta versier nie ook 'n wyse om kerklike voorgangers te onthou nie? Hulle word dikwels uitgebeeld "als iconen van bijbelse spiritualiteit of ingetogen vroomheid". 42 'n Sprekende voorbeeld hiervan is die portret van Andrew Murray.

In die dosente raadsaal van die Fakulteit Teologie op Stellenbosch hang 24 mense se portrette, en almal is mans. Op drie na (al drie van ná 1994), is al die mans ook blank. Agter daardie wit mans se portrette sou 'n mens jou eintlik 'n hele onsigbare netwerk van vrouens en swart- en bruinmense kan voorstel wat dit vir hierdie spesifieke wit manlike individue moontlik gemaak het om teen die muur te pryk. Is hier nie 'n skreiende wanbalans ten opsigte van wie as geloofsvoorgangers in die protestantisme afgebeeld en afgeneem en sodoende onthou is nie? Ja, waar is selfs die gelowiges sonder teologiese grade? Waar is diegene wat ter wille van die Evangelie 'n profetiese stem teen apartheid laat opgaan het? ${ }^{43}$

Afgesien van hierdie wanbalans, is dit egter ook belangrik om die potensiaal van hierdie portrette raak te sien. Hier is 'n medium wat in die geskiedenis nooit as afgodery beskou is nie, en wat op doeltreffende wyse sekere voorouers onthou het, asook sekere waardes deur middel van hulle bepaalde maskering gekommunikeer het en steeds kommunikeer. ${ }^{44}$ Daarom sal in die volgende (laaste) afdeling van hierdie verkenning al die verskillende onderafdelings bymekaar getrek word om te interfereer ${ }^{45}$ en uit te vind of hierdie portrette oor inkultureerbare ${ }^{46}$ kwaliteite beskik ten opsigte van die voorouers in Christelike kerke in Afrika.

\section{Inkultureerbaar?}

Gedurende veldwerk in die VGK Langa het dit geblyk dat foto's 'n besondere betekenis het in die lewe van Afrikane, en dat hulle aan foto's spesiale eienskappe toeskryf. ${ }^{47}$ Wat die

41. Vergelyk, Frijhoff, W 1998. Heiligen, idolen, iconen. Rede in verkorte vorm uitgesproken bij de openbare aanvaarding van het ambt van gewoon hoogleraar in de geschiedenis van de Nieuwe Tijd aan de Vrije Universiteit te Amsterdam op donderdag 28 mei 1998. Nijmegen: SUN, p. 42.

42. Ibid., p. 41.

43. Uiteraard kan daar in die seleksie van voorgangers nooit anders as selektief te werk gegaan word nie, en is hierdie eensydig manlike prentjie verstaanbaar. Desnieteenstaande sal dit juis Evangelies wees om hierdie visuele boodskap te inkultureer en ongelykhede aan te spreek. Dieselfde beginsel behoort dan ook te geld ten opsigte van die voorouers in die Afrika konteks wat meesal ook net swart en manlik is.

44. Vergelyk, Wepener, CJ en Cilliers, J 2003. "Portrette wat praat: Gereformeerde 'konsistorie-kuns' as locus theologicus?". Ongepubliseerde artikel.

45. "Interference is a term that chiefly has its roots in physics, especially in connection (with movements) of vibrations of light and sound waves, where it denotes the reciprocal effects of the movements on one another. This interaction or reciprocal effect can hinder and disrupt, but can also reinforce and enrich". Post, PGJ 2001. "Introduction and application. Feast as a key concept in a liturgical studies research design". In: Post, PGJ et al. Christian Feast and Festival. The Dynamics of Western Liturgy and Culture. Liturgia Condenda 12. Leuven: Peeters, p. 58-59.

46. Inkulturasie dui op 'n krities wederkerige integrasie tussen die Evangelie/liturgie en die kultuur waar beide mekaar krities belig. Vir meer oor dié konsep sien, Amallorpavadoss, DS 1990. "Theological Reflections on Inculturation Parts 1 \& 2". Studia Liturgica 20, 36-54 \& 116-136, Lukken, G 1994. Inculturatie en de toekomst van de liturgie. Heeswijk-Dinther: Uitgeverij Abdij van Berne, asook, Van Tongeren, L 1996. "De inculturatie van de liturgie tot (stil)stand gebracht?". Jaarboek voor liturgie-onderzoek 12, 164-186.

47. Die veldwerk (deelnemende observasie) is tussen Februarie en Oktober 2002 deur die skrywer van die artikel gedoen. So byvoorbeeld het 'n Xhosa man die volgende uitlating gemaak ten opsigte van die betekenis van foto's vir swartmense. "Dit (foto's) beteken baie. Byvoorbeeld, 'n kleinkind kan nie haar ma onthou nie omdat die dood is toe sy baie klein was, maar as sy 'n foto het kan sy haar vriendjies roep en die foto wys en 
inkulturatiewe potensiaal van foto's aanbetref het een predikant sover gegaan as om te sê: "Mense kom nou deesdae, soos ek jou al baie gesê het, kwaai terug na hulle 'roots' toe. Want kyk, die mense het nou kom 'teach' dat julle nie meer mense gaan wees sonder julle tradisie en gebruike en roots nie, want sonder dit het julle nie meer julle 'identity' nie. Dus begin die mense dus begryp ons moet teruggaan na die 'roots' toe. En daarom is die foto's in die kerk 'n goeie idee vir die mense wat nie in die kerk is nie, omdat hulle nog dink die kerk teen hulle swart 'roots' is. Dit sal maak dat mense op 'n 'practical' manier weer terugkom, want mense sal sien, en sien is vir ons swartmense baie belangrik, hulle sal sien die kerk, die kerk die respekteer ons gebruike". ${ }^{48}$

Vervolgens sal eerstens enkele kwaliteite wat afgelei kan word uit elk van die voorafgaande onderafdelings puntsgewys aangegee word. Daarna sal gekyk word of (gefotografeerde) dominee-portrette oor die kwaliteite beskik wat nodig is om voorouers in 'n Afrikakonteks te onthou en so te vereer, en indien wel, of dit 'n Skriftuurlike ontwikkeling sal wees:

- Postmortem fotografie: familie as konteks; ontkenning van die dood; werklikheid van dood vanweë fotografie as medium; help met treur/rou; onthou subjek as lewend, al is dood; in fotografie, anders as in die skilderkuns, is 'n pyp 'n pyp en 'n lyk 'n lyk; uitdrukking van persoon se identiteit en individuele waarde; behoeftebevrediging ten opsigte van versekering van lewe na die dood wat nie op Skrif gefundeer is nie

- Dodemaskers: rigidifiseer/vasgelê; bonatuurlike krag/magiese kousaliteit/dunamis; simbool van spirituele band tussen lewe en dood; onthou/geheue om oorledene teenwoordig te stel vir aanskouer.

- Voorouers: familie en gemeenskap as konteks; vereer/diens; "lewende dooies"; onthou as mense; praat oor voorouers; in herinnering geroep; geloof as kriterium binne geloofsgemeenskap.

- Gelowige getuies: liggaam van Christus as konteks; geloofsvoorgangers eerder as heiliges; gemeenskap van heiliges strek oor dood heen; Skriftuurlik; ouditief en visueel onthou in die liturgie.

- Dominee-portrette: plaaslike gemeente of kerkverband as konteks; kompensasie op beeldloosheid; stel sekere spiritualiteit voor; patriargaal; mono-kultureel; slegs binnestanders; potensiaal om dooies as lewendes te onthou.

Vanweë die aard van fotografie as 'n medium (wat anders is as die medium wat Magritte aangewend het om 'n pyp mee uit te beeld), is 'n pyp hier altyd 'n pyp. Desnieteenstaande, anders as in postmortem fotografie is (gefotografeerde) dominee-portrette se subjekte, alhoewel dikwels nie meer met ons nie, ook nie dood nie. Hulle is inderdaad lewende dooies. Tog, as lewende dooies is selfs hulle foto-gebonde dood-transenderende visuele teenwoordigheid ook gebonde aan tyd. Ja, Chronos is ' $\mathrm{n}$ vismot wie se verwoestingswerk ook al duidelik sigbaar is in die deteriorasie van baie dominee-portrette. Dit is as 'n fisiese proses sigbaar in die foto's self, maar ook in die geheue van opvolgende geslagte. Lank lewe die dooies, en alreeds sterf die lewende dooies. Dominee-portrette is dus geen poging om die subjek onsterflik te maak, soos byvoorbeeld die pogings om Lenin deur middel van balseming en welriekendheid (die sogenaamde geur van heiligheid) onsterflik te maak

sê: 'kyk, hier's my ma'. En dít, die foto, dit sit diep in jou hart. Sy ma bly dus deur die foto lewendig in sy hart. Die persoon wat afgesterwe het, bly so deur die foto lewendig in jou hart".

48. Die aktuele invoering van elemente uit die Afrika kultuur in die Christelike erediens vra egter groot omsigtigheid vanweë uiteenlopende standpunte in hierdie verband. 
nie. ${ }^{49}$ Portretfotografie is alleen 'n poging om tydelik (geloofs)ouers te onthou, en 'n ideale geleentheid om memento mori vir 'n paar geslagte om te sit in memento mortuos sicut vivendi (sind). ${ }^{50}$

In Afrika word die voorouers ook vir vier of vyf geslagte lank onthou en slegs enkele voorouers soos Shaka sal vir altyd onthou word. ${ }^{51}$ Fisiese ruimte ten opsigte van die vertoning van protretfoto's van die voorouers behoort dus nie 'n probleem te raak nie, aangesien die meeste na 'n paar generasies gewoon in 'n voorouer-argief gebêre kan word om sodoende plek te maak vir die volgende generasie voorouers. Só 'n gebruik sou ook keer dat die objek self, die foto, gevenereer word as 'n spesiale objek met bonatuurlike kragte.

Verder is indringende inkulturasie ten opsigte van wie vertoon moet word nodig. Die tradisionele patriargale, binnestander paradigma moet vervang word met 'n eg Bybelse verstaan dat God geen onderskeid tussen mense maak gebaseer op ras, geslag of sosiale status nie, maar dat die geloof as produk van die Woord en die Gees die enigste Christelike kriterium is. Dít uiteraard binne 'n bepaalde historiese konteks waarbinne sommige attribute van die geloof in sekere eras meer waardeer sal word as ander, en binne 'n bepaalde kultuur-gebonde plaaslike gemeente. Desnieteenstaande moet die lig van die Skrif val op die kies van voorouers wat onthou word, asook op die hele dominee-portret tradisie. Die multi-kulturele Suid-Afrikaanse opset moet ook in ag geneem word en krities die mono-kulturele dominee-portret tradisie aanspreek.

Benewens die konteks van Afrika en die Christendom, is dit ook noodsaaklik om die hedendaagse beeld-kultuur in ag te neem. ${ }^{52}$ Van alle kante word die mens gebombardeer deur 'n stortvloed van beelde wat almal 'n indruk laat op die mens. Die beelde waardeur ons omring word, kommunikeer waardes aan ons en vorm ons. Dit is dus uiters noodsaaklik om hierdie konteks ook in ag te neem en in diens van die Evangelie te stel. Daarom is die portret-foto's as een visuele medium van baie protestantse kerke en dikwels ook die mees prominente visuele medium, 'n bruikbare medium wat alreeds bestaan en benut kan word.

Verder is dit 'n Skriftuurlike gegewe dat die gemeenskap van gelowiges oor die grense van lewe en dood heen strek. Voorts is die Bybelse kriterium vir geloofsgetuies, geloof. Die vraag is egter hoe geloof gemeet kan word om sodoende vas te stel wie dan nou die meeste geloof gehad en as sodanig visueel onthou moet word? Hier moet 'n mens uiters omsigtig te werk gaan en oppas vir 'n subjektiwistiese siening van geloof as menslike attribuut, maar tog onthou dat die Bybel self nie skroom om mense wat besondere eksponente van geloof was, uit te sonder en te onthou nie.

Ten slotte is dit belangrik om in ag te neem dat die finale seggenskap ten opsigte van die betekenis van die foto's subjektief gebonde is aan die aanskouer se interpretasie en toeeiening van die beeld. Hierdie interpretasie is egter ook weer konteks gebonde, en daarom

49. Sien, Frijhoff, W, p. 32-35. "Zo bepaalde patriarch Nectarius van Jeruzalem in 1680 dat de heiligheid van een persoon naast de door hem of haar verrichte wonderen moest blijken uit de onbedorven staat waarin het lichaam na de dood bewaard was, of in elk geval uit de geur van heiligheid die bij openmaking van het graf uit de resten moest opstijgen".

50. "Om die dooies as lewendes te onthou".

51. Vergelyk, Crafford, D 1996, p. 15.

52. Vergelyk onder andere, Babin, P 1991. The New Era in Religious Communication. Minneapolis: Fortress Press, Cilliers, JH 2002. "Prediking as verbeelding: moontlikhede vir eietydse verkondiging" waar hy praat van 'n "kultuur van beelde", asook Lukken wat in sy mees resente werk opmerk dat in ons kultuur (Europese) die beeld, die visuele oorheers, Lukken, G 1999. Rituelen in overvloed. Een kritische bezinning op de plaats en de gestalte van het christelijke ritueel in onze cultuur. Baarn: Gooi \& Sticht, en, Power se hoofstuk 6 getiteld "Seeing is believing: The force of the visual", Power, DN 1999, p. 178-208. 
is dit belangrik om te onthou dat die fisies-ruimtelike konteks van hierdie portrette, die kerkgebou, of nog beter, die Christelike liturgie moet wees. Sodoende word die gevaar uitgeskakel dat die foto's van mense die sentraliteit van Christus in die Christelike liturgie en ander paraliturgiese ruimtes sal verdring, aangesien die fokus van die Christelike liturgie altyd die Drie-enige God moet wees. Die foto's behoort hierdie ononderhandelbare gegewe te dien. Gefotografeerde geloofsgetuies wat heenwys na die hoop wat geleë is in die Vader, Seun en Heilige Gees.

\section{Ten slotte}

Die egtheid van die werklikheid van fotografie lê op materiële wyse 'n temporele verbintenis tussen lewendes en dooies, sodat die dooies as lewendes onthou word en sodoende via die lewendes se geheue en verbeelding teenwoordig gestel word. ${ }^{53}$ Laasgenoemde proses is soortgelyk aan die oorspronklike funksie van dodemaskers, maar sonder enige magiese potensiaal. Soortgelyk aan postmortem fotografie, maar sonder ' $\mathrm{n}$ ontkenning van die dood - eerder 'n sluit van 'n kring van getuies oor die grense van die dood heen. Dit is bykans soos die tradisionele dies natalis, die sterfdag van 'n Christen wat in Latyn sy/haar geboortedag genoem is. Op soortgelyke wyse bring fotografie die idee van die reële bestaan van lewe na die dood, en daarmee saam die moontlikheid van hoop, nader aan lidmate. Hierdie funksie wat inherent is aan die aard van fotografie as medium, is anders as byvoorbeeld die "In loving memory of..." koperplaatjies wat in baie kerke aangetref word, wat as medium eerder die dood as die lewe aksentueer. Foto's van lewende oorlede gelowiges lê eerder die klem op die lewe. Hier sou 'n mens tereg kon sê, "The medium is the message", ${ }^{54}$ en is die boodskap van diesulke foto's as medium 'n uittartende "Dood, waar is jou angel?". Die foto's onderstreep dus sodoende die teologiese waarheid en onderbou van hierdie ondersoek, te wete die kontinuïteit wat bestaan tussen lewende en dooie gelowige getuies.

Verder is die konteks waarbinne gelowige getuies funksioneer die liggaam van Christus (wat veel meer is as net 'n metafoor) wat nie tyd-ruimtelik gebonde is nie. Dit is 'n liggaam wat uit gelowiges bestaan (in watter werklikheid hulle hulself ookal mag bevind), en dié waarheid kan juis ook gedien word deur die inkulturasie van die lewende dooies deur die gebruikmaking van portret-fotografie.

Die subjektiewe reaksie wat 'n postmortem foto by die gemiddelde kyker oproep, is uiters negatief. Dit hang uiteraard saam met ons hedendaagse kultuur wat sku is vir die dood en die onderwerp vermy soos wat seks as onderwerp vermy is in die negentiende eeu. 'n Verdere en meer belangrike rede is die feit dat hier volgens Barthes 'n perverse verwarring van twee konsepte voorkom, te wete die Egte en die Lewendige. "[B]y attesting that the object has been real, the photograph surreptitiously induces belief that it is alive, because of that confusion which makes us attribute to Reality an absolutely superior, somehow eternal value. ${ }^{55}$ Daarom is die onnabootsbare unieke eienskap van fotografie die feit dat iemand in vlees en bloed, 'n persoon, die subjek was. En juis hierdie unieke

53. So byvoorbeeld kyk Karel Schoeman na 'n ou foto van Olive Schreiner en die mense van die plaas Klein Gannahoek waar sy as goewernante gewoon het en skryf: "Daardie mense, haas onménslik in hul stywe outydse kleding, en daardie eenvoudige plaasgeboutjie was alles eens deel van dieselfde werklikheid; en daardie mense was almal dood en die geboutjie het nie meer bestaan nie, maar hier op die papier is hulle desondanks vasgevang en sodoende verewig. Hierdie besondere bewustheid of gewaarwording vind ek moeilik om nader te omskrywe...". Schoeman, Karel 2002. Die laaste Afrikaanse boek. Outobiografiese aantekeninge. Kaapstad/ Pretoria/ Johannesburg: Human \& Rousseau, p. 235-236.

54. Uitspraak van Marshall McLuhan.

55. Barthes, R 1980, p. 79. 
eienskap van die aard van fotografie, maak dit die ideale medium om die voorouers van Afrika in die Christelike kerk te onthou as lewende dooies. "From a real body, which was there, proceed radiations which ulimately touch me, who am here; the duration of the transmission is insignificant; the photograph of the missing being, as Sontag says, will touch me like the delayed rays of a star. A sort of umbilical cord links the body of the photographed thing to my gaze: light, though impalpable, is here a carnal medium, a skin I share with anyone who has been photographed". ${ }^{56}$

\section{Figuur 6:}

Foto van Lewis Payne wat gepoog het om 'n politikus om die lewe te bring. Hier is hy in sy sel waar hy wag om gehang te word, gefotografeer deur Alexander Gardner. Volgens Barthes, "He is dead and he is going to die...". 57

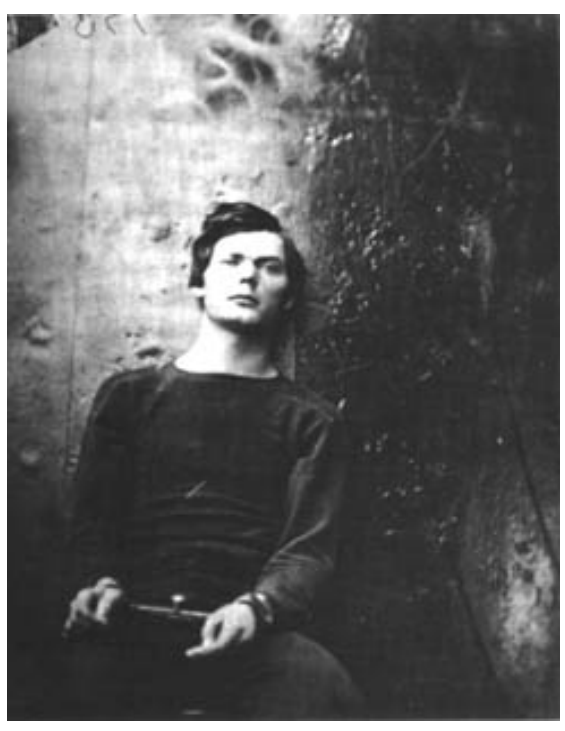

56. Ibid., p. 81 .

57. Uit, Barthes, R 1980, p. 95. 